\title{
КЛАССИФИКАЦИЯ ФОРМ СВЯЗАННОЙ ВОДЫ В КАОЛИНИТОВЫХ ГЛИНАХ
}

\author{
Середин Валерий Викторович1, \\ seredin@nedra.perm.ru
}

\section{Ядзинская Марина Радиковна', marinayadzinskaya@mail.ru}

\author{
Андрианов Андрей Владимирович², \\ andrianov@nedra.perm.ru \\ 1 Пермский национальный исследовательский университет, \\ Россия, 614990, г. Пермь, ул. Букирева, 15. \\ 2 ООО НИППППД «Недра», \\ Россия, 614064, г. Пермь, ул. Льва Шатрова, 13а.
}

\begin{abstract}
Актуальность. Вода является важнейшей компонентой грунтов, так как оказывает влияние на основные геологические процессы. Это объясняется особенностями ее состава и строения. Многие ученье занимались изучением вопроса содержания связанной воды в глинах. Однако экспериментов по данному вопросу недостаточно.

Целью данной работы является изучение форм связанной воды в каолинитовых глинах, отжимаемых при высоких давлениях, а также выявление связи между потерями масс воды под давлением и термодинамическими параметрами.

Объект исследования - каолинитовые глины.

Метод. Для достижения цели были подготовлены образцы каолинитовой глины с различной степенью обжатия под давлением. Затем проводился термогравиметрический анализ, в ходе которого измерялись потери массы связанной воды при нагревании до 1000 ㄷ. С помощью атомно-силового микроскопа изучалось влияние шероховатости на количество отжимаемой связной воды из образцов каолинитовой глины.

Результаты опытных данных и анализ термограмм позволили выделить четыре пика потери массы воды, в соответствии с этим предложена классификация связанной воды в глине: рыхлосвязанная вода поверхности коллоидов; прочносвязанная вода поверхности коллоидов; вода поверхности минералов; вода кристаллической решетки. Воздействие высокого давления на массу удаляемой воды неоднозначно. Это связано с тем, что под давлением происходит образование дефектов, как следствие изменяется энергетический потенциал и сорбционная активность глинистых частиц. При этом выявлена тесная связь между показателем шероховатости и градиентом удаляемой связанной воды в интервале давлений от 0 до 200 МПа. При давлениях от 200 до 800 МПа связь не установлена.
\end{abstract}

\section{Ключевые слова:}

Каолинитовая глина, формы связанной воды, термогравиметрия, давление, удельная поверхность, шероховатость, сорбционная активность.

\section{Введение}

Все грунты в своем составе содержат воду. С этой компонентой не сравнится никакая другая по влиянию на ход основных геологических процессов. Прежде всего, уникальность воды как компоненты обусловлена ее свойствами, составом и строением. Многие ученые, такие как Е.М. Сергеев, Р.И. Злочевская, 3.А. Кривошеева, В.А. Королев [1, 2], Э.А. Гойло [3, 4], E. Galan [5] и другие [6-10] занимались изучением вопроса содержания связанной воды в глинах.

Р.И. Злочевская и др. описывали изменение свойств связанной воды в глинах при увеличении давлений и температур. По данным изыскателей [1-5] в первую очередь при воздействии давлений на грунт удаляется свободная, затем осмотическая вода, а адсорбционно-связанная вода отжимается из глинистого грунта только при нагрузках более 10 МПа. Ближайшие к твердой компоненте грунта слои воды не удаляются при нагрузках в десятки МПа.
Изучение влияния стрессового давления на количество связанной воды является очень важным, так как во многом определяет свойства глин.

Целью данной работы является изучение форм связанной воды в каолинитовых глинах, отжимаемых при высоких давлениях, а также выявление связи между потерями масс воды под давлением и термодинамическими параметрами.

Объектом исследования являлась каолинитовая глина, добываемая Челябинским рудоуправлением на «Нижне-Увельском» месторождении. Залежи глин представлены отложениям наурзумской свиты миоцена $\left(N_{1} n r\right)$ озерно-аллювиального происхождения. Мощность свиты достигает 20 м. Глины используются в огнеупорной промышленности и в производстве керамики.

Опыты проводились на образцах, которые получены в результате обогащения Челябинского каолина методом седиментации. Всего исследовано около 100 образцов. Средние значения минерального и фракционного состава глин представлены в табл. 1, 2. Выборка формировалась случайным образом с небольшой вариацией по гранулометрическому составу. 
Таблица 1. Минеральный состав каолинитовой глины

Table 1. Mineral composition of kaolinite clay

\begin{tabular}{|c|c|c|c|}
\hline \multirow{2}{*}{$\begin{array}{c}\text { Наименование } \\
\text { образца } \\
\text { Sample name }\end{array}$} & \multicolumn{3}{|c|}{ Содержание минералов/Mineral content, \% } \\
\hline & $\begin{array}{c}\text { монтмориллонит } \\
\text { montmorillonite }\end{array}$ & $\begin{array}{c}\text { каолинит } \\
\text { kaolinite }\end{array}$ & $\begin{array}{l}\text { кварц } \\
\text { quartz }\end{array}$ \\
\hline $\begin{array}{l}\text { каолинитовая глина } \\
\text { kaolin clay }\end{array}$ & 15 & 77 & 8 \\
\hline
\end{tabular}

Таблица 2. Фракиионный состав каолинитовой глины

Table 2. Fractional composition of kaolinite clay

\begin{tabular}{|l|c|c|c|c|}
\hline \multirow{2}{*}{$\begin{array}{c}\text { Наименование образца } \\
\text { Sample name }\end{array}$} & \multicolumn{4}{|c|}{ Содержание частиц/Mineral content, \% } \\
\cline { 2 - 5 } & $>50$ мкм & $\begin{array}{c}5-50 \text { мкм } \\
5-50 \mu \mathrm{m}\end{array}$ & $\begin{array}{c}1-5 \text { мкм } \\
1-5 \mu \mathrm{m}\end{array}$ & $\begin{array}{c}<1 \text { мкм } \\
<1 \mu \mathrm{m}\end{array}$ \\
\hline $\begin{array}{l}\text { каолинитовая глина } \\
\text { kaolin clay }\end{array}$ & 0 & 34 & 52 & 14 \\
\hline
\end{tabular}

\section{Методика исследования}

Сущность методики исследования

1. Подготовка образца происходила с помощью испытания давлением для дальнейшего проведения опытов в термоанализаторе. Образцы глин проходили специальную обработку. Грунты отмучивались в дистиллированной воде, затем высушивались в специальных сушильных шкафах до постоянной массы. Высушенные образцы растирались в ступке пестиком с резиновым наконечником.

Далее образцы обогащенной глины массой 0,2 г были подвержены сжатию на приборе высокого давления. При давлениях, равных 10, 25, 35, 50, 75, 85, 100, 115, 125, 150 МПа, далее через каждые 50 МПа до 800 МПа изготавливалось по 3-5 образцов (для каждой ступени давления) в виде «таблеток». Затем образцы глин в течение семи суток выдерживались в эксикаторе. Таким образом изготовлено примерно 100 образцов.

2. Термогравиметрический анализ, совмещенный с масс-спектральным анализом, заключался в измерении потери массы воды при нагревании до
$1000{ }^{\circ} \mathrm{C}$ каждого образца глины, обработанного при заданных давлениях.

\section{Оборудование и приборы:}

- ступка фарфоровая;

- пестик с резиновым наконечником;

- весы лабораторные;

- термоанализатор STA 409 PC Luxx;

- атомно-силовой микроскоп (АСМ);

- эксикатор;

- дифрактометр D2 Phaser;

- сушильный шкаф

\section{Проведение испытаний}

Каждую специально подготовленную «таблетку» грунта в корундовом тигле нагревали до температуры $1000{ }^{\circ} \mathrm{C}$, температура увеличивалась на $10{ }^{\circ} \mathrm{C}$ каждую минуту. Термогравиметрический анализ (ТГ) и дифференциальная сканирующая калориметрия (ДСК) проводились с помощью термоанализатора.

С помощью атомно-силового микроскопа измерялась шероховатость $\left(R_{c}\right)$ и удельная поверхностная энергия $(\gamma)$.

Размер области когерентного рассеивания толщины кристаллита (минерала) $\left(\mathrm{M}_{\mathrm{K}}\right)$ определялся с помощью дифрактометра.

\section{Результаты исследования}

На основании полученных опытных данных построены термограммы изменения массы отжимаемой воды при нагревании до $1000{ }^{\circ} \mathrm{C}$ в процентах от первоначальной массы. На рис. 1, 2 в качестве примера приведены термограммы образца глины, подготовленного сжатием 10 МПа. Анализ изменения ТГ-кривых каолинитовой глины показывает, что здесь наблюдается четыре экстремума кривой, которые зафиксированы при температурах испытаний 90, 150, 500, $800{ }^{\circ} \mathrm{C}$.

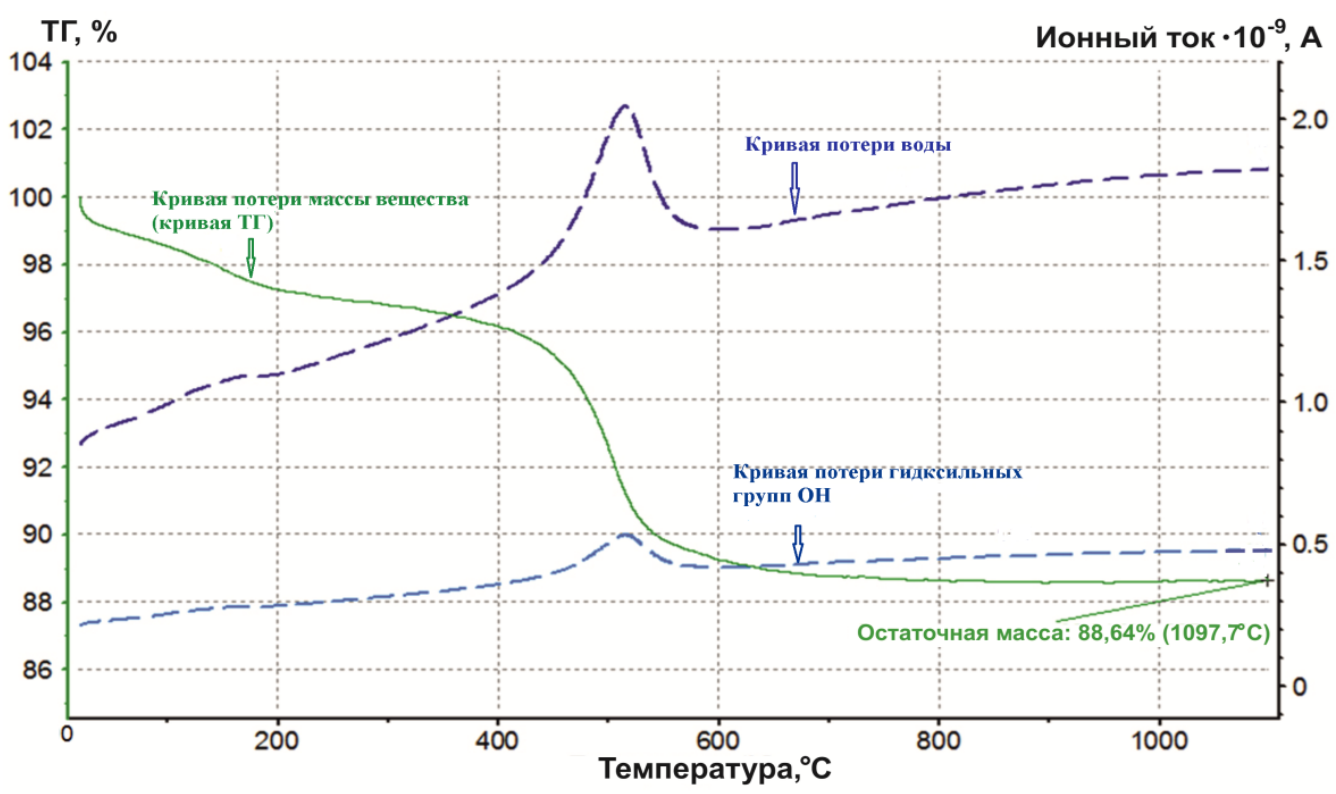

Puc. 1. Термограмма по данным масс-спектрального анализа газовой фазы

Fig. 1. Thermogram based on gas phase mass spectral analysis data 


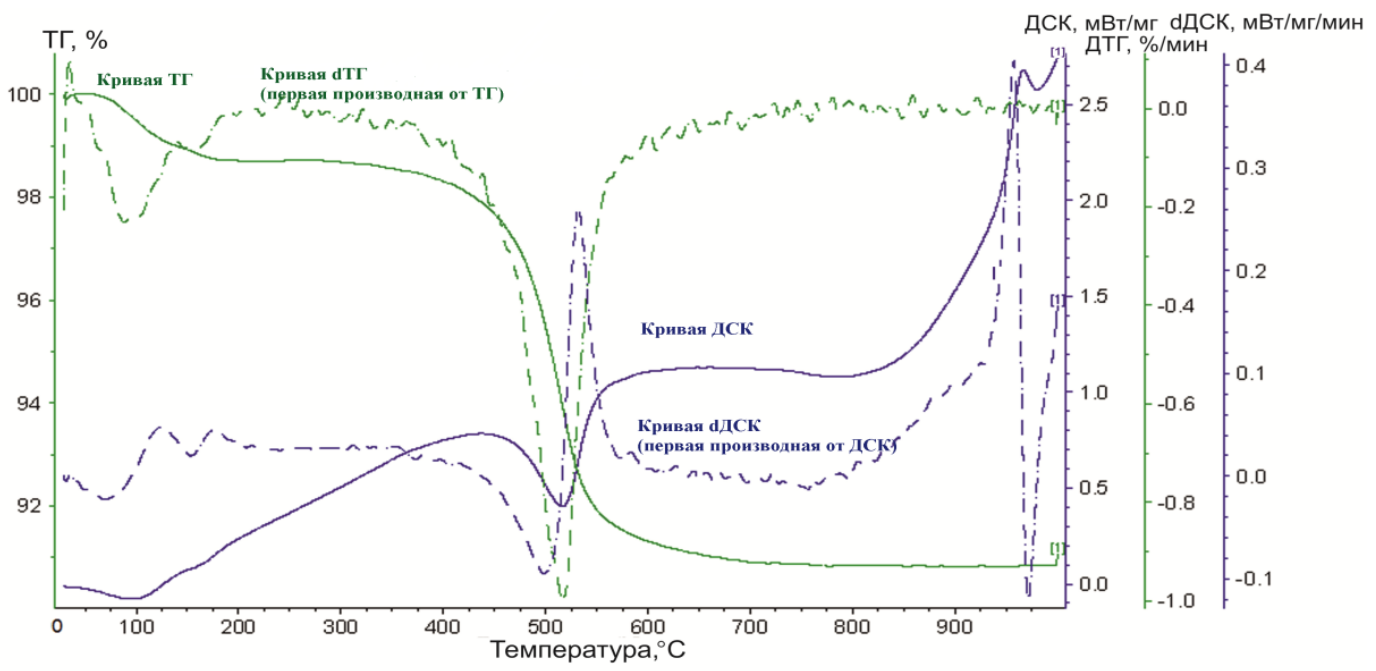

Pис. 2. Термограмма по данным дифференциальной сканирующей калориметрии (ДСК)

Fig. 2. Thermogram based on differential scanning calorimetry (DSC) data

Основываясь на полученных опытных данных, можно заключить, что глины содержат определенное количество поверхностной адсорбированной воды (рыхлосвязанной и прочносвязанной). Выделение воды, которое происходит при температуре $90-150{ }^{\circ} \mathrm{C}$, связано с потерей массы рыхлосвязанной $\left(1\right.$ класс $\left.-\mathrm{m}_{\mathrm{p}}\right)$ и прочносвязанной форм воды $\left(2\right.$ класс $\left.-\mathrm{m}_{\Pi}\right)$. Это вода поверхности коллоидов. Выход гидроксильных групп из кристаллической структуры минералов происходит при температурах от 500 до $800{ }^{\circ} \mathrm{C}$. Выделение воды, которое происходит при температуре $500{ }^{\circ} \mathrm{C}$, соответствует третьему классу - вода поверхности минералов $\left(\mathrm{m}_{\mathrm{oH}^{-}}\right)$. Температура выделения воды и ОН-групп зависит от размера коллоидов и глинистых агрегатов, совершенства кристаллической структуры минералов и условий эксперимента. При температуре $800{ }^{\circ} \mathrm{C}$ выделяется вода кристаллической решетки минералов $\left(4\right.$ класс $-\mathrm{m}_{\text {пк }}$ ). При температурах свыше $900{ }^{\circ} \mathrm{C}$ кристаллическая решетка начинает разрушаться. Предложенная авторами классификация воды соотносится с классификацией Е.М. Сергеева и др.

Под водой кристаллической решетки понимается высвобождающиеся гидроксил-ионы $\left(\mathrm{OH}^{-}\right)$.

Глинистые грунты претерпевают изменения не только под действием температур, но и в результате воздействия высоких давлений. К такому выводу пришли при анализе графиков (рис. 3) изменения потери массы воды образцов, обработанных при всех 25-ти ступенях давлений. Так, на рис. 3, а показаны потери массы воды образцов, подвергшихся нагреванию при температуре, характерной для выделения рыхлосвязанной воды $\left(90^{\circ} \mathrm{C}\right)$, обжатых при различных давлениях.

Из рис. $3, a, \sigma$ видно, что с увеличением давления потеря массы рыхлосвязанной и прочносвязанной воды возрастает. Для воды поверхности минерала (рис. 3, в) такая закономерность наблюдается только до нагрузки 125-200 МПа, при дальнейшем увеличении нагрузки наблюдается обратная зависимость. Увеличение массы отжимаемой воды кристаллической решетки (рис. 3, г) происходит только начиная с нагрузки от $200 \mathrm{MПа.}$
Для проверки связи между потерей массы воды и увеличением давления был проведен корреляционный анализ, который показал наличие более сильной связи между давлением на образец в интервале значений от 0 до 200 МПа и массой отжимаемой связанной воды. При давлениях более 200 МПа связь между этими показателями менее выражена.

Данные факты говорят о том, что в первую очередь происходит отжим рыхло- и прочносвязанной воды (1 и 2 класс). Вода поверхности кристаллита (минерала) отжимается до нагрузки 200 МПа, затем наблюдается некоторое уменьшение потерь этой формы воды. Это объясняется тем, что в глине при увеличении давлений более 200 МПа происходит изменение структуры, наблюдаются параллельные процессы дробления и агрегации [11-20] глинистых частиц и как следствие изменение удельной поверхности и энергетического потенциала глинистых частиц.

При стрессовых давлениях происходит разрыв водородных связей между двухэтажными элементарными пакетами каолинита, что приводит к неупорядоченности в наложении слоев и их смещению друг относительно друга. Таким образом, часть внутренних гидроксилов начинает удаляться при более низких температурах, увеличивая потери массы $\mathrm{OH}^{-}$-групп на поверхности кристаллитов (минералов). В то же время за счет увеличения дефектности кристаллической структуры каолинита и в результате агрегации глинистых частиц часть гидроксилов оказывается в «ловушке» и начинает отжиматься при очень высоких температурах. Это объясняет увеличение потерь масс внутренних гидроксилов при давлениях свыше 200 МПа (рис. 5, в).

Следует отметить, что удельная поверхностная энергия зависит от изменяющейся под давлением структуры каолинита и от образования дефектов на поверхности частиц глины, так называемой «шероховатости». Под шероховатостью в данном случае понимается морфология поверхности глинистой частицы. Подробно методика определения шероховатости, расчет среднеарифметической шероховатости $\left(\mathrm{R}_{\mathrm{c}}\right)$, изложена в работах В.В. Середина, М.В. Федорова и др. [21-22]. 
$a / a$

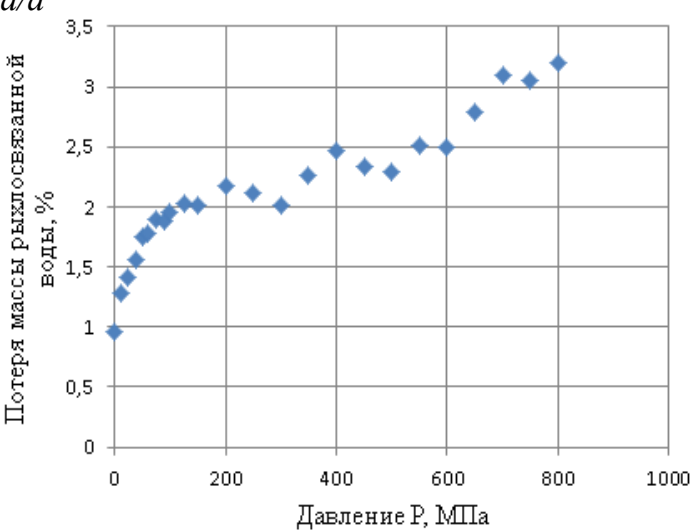

B/c

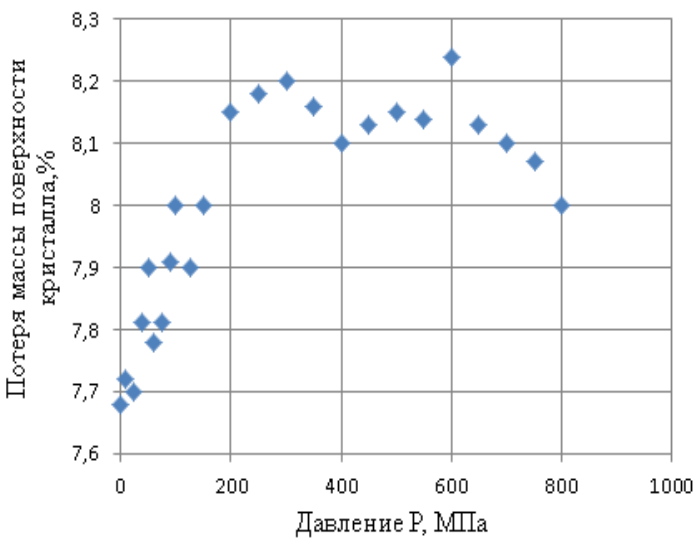

$6 / b$

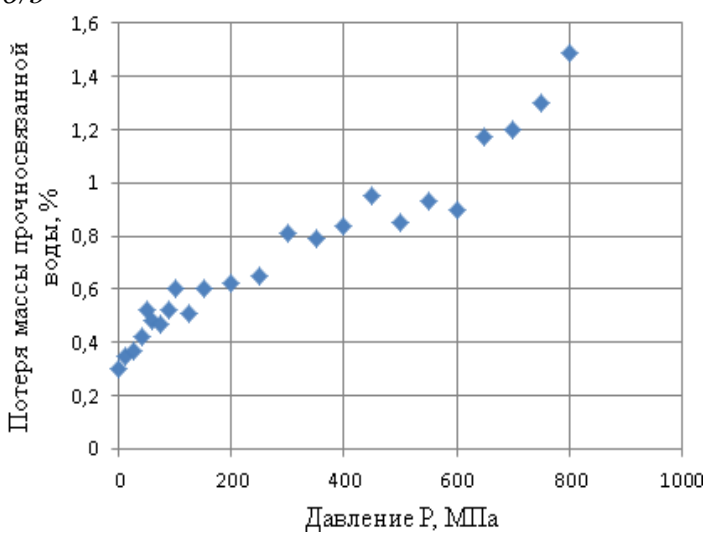

$2 / d$

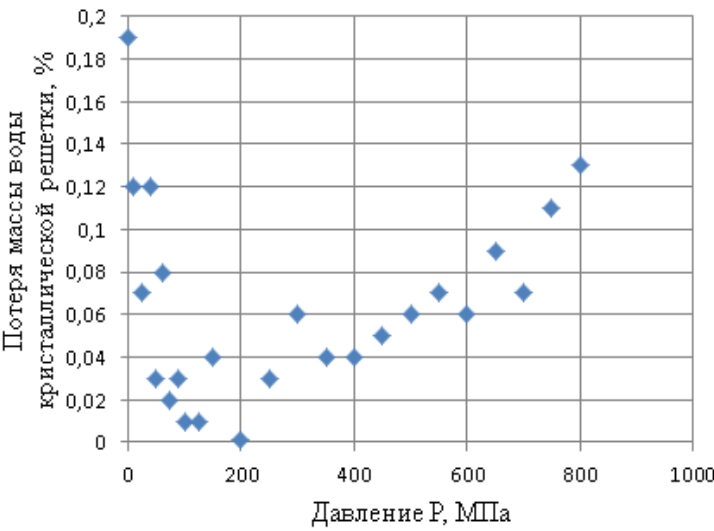

Рис. 3. Диаграмма рассеяния показателей: а) потери массы рыхлосвязанной воды (тр) и давления (Р); б) потери массы прочносвязанной $\left(m_{n}\right)$ воды коллоида и давления $(P)$; в) потери массы воды поверхности кристаллита (минерала) $\left(m_{\text {он }}\right)$ и давления $(P)$; г) потери массы кристаллической решетки минерала $\left(m_{n \kappa}\right)$ и давления $(P)$

Fig. 3. Scatter diagram of indicators: a) loss of mass of loosely bound water $\left(m_{r}\right)$ and pressure $(P)$; $\left.b\right)$ loss of mass of strongly bound $\left(m_{p}\right)$ water of the colloid and pressure $\left.(P) ; c\right)$ loss of water mass of the crystallite (mineral) surface $\left(m_{\text {oн }}\right)$ and pressure $(P) ; d)$ loss of mass of the crystal lattice of the mineral $\left(m_{p c}\right)$ and pressure $(P)$

Поэтому изучение взаимосвязи между изменяющейся структурой глинистых частиц и массой отжимаемой воды является неотъемлемой частью данной работы.

В.Г. Шлыков в своей работе очень подробно описывал влияние дефектности (несовершенства) кристаллических структур каолинитовых глин на их свойства [11]. Согласно его данным наиболее информативным показателем несовершенства структуры является размер области когерентного рассеивания $\left(\mathrm{M}_{\mathrm{\kappa}}\right)$, причем чем ниже этот показатель, тем более несовершенна структура и соответственно выше удельный энергетический потенциал частицы.

На основе проведенных нами исследований были построены диаграммы рассеивания показателя толщиины кристаллита (минерала) $\left(\mathrm{M}_{\mathrm{K}}\right)$ и массы удаляемой воды в процентах (рис. 4).

На основании диаграмм рассеяния (рис. 4) установлено, что при увеличении удельного энергетического потенциала (т. е. с уменьшением $\mathrm{M}_{\mathrm{K}}$ и увеличением дефектности структуры) наблюдается увеличение удаляемой массы всех форм воды. Это говорит о прямой связи влияния несовершенства структуры кристаллита (минерала) на сорбционную активность глин.

В работах [12-22] подробно изучались вопросы влияния морфологии или шероховатости поверхности глинистой частицы на изменение удельной поверхностной энергии. А изменение удельной поверхностной энергии частиц, в свою очередь, влияет на количество связной воды, удерживаемой на ее поверхности. Поэтому важно оценить влияние шероховатости поверхности частиц на количество удаляемой воды из каолинитовой глины.

На рис. 5 приведены диаграммы рассеивания между шероховатостью $\left(\mathrm{R}_{\mathrm{c}}\right)$ поверхности частиц и изменением удаляемой массы воды всех форм.

По диаграммам рассеивания (рис. 5) наблюдается некоторая закономерность увеличения потерь всех форм воды с увеличением шероховатости. Но такая закономерность прослеживается только до значений шероховатости $\mathrm{R}_{\mathrm{c}}<100$ нм, которая формируется при давлениях до 200 МПа. При более высоких значениях $\mathrm{R}_{\mathrm{c}}$ и соответственно давлениях более 200 МПа выявить подобную закономерность не удалось. Корреляционный анализ подтверждает, что уменьшение массы рыхло-, прочносвязанной воды и воды поверхности кристаллитов (минералов) при нагрузках до 200 МПа тесно связано с изменением шероховатости $\left(\mathrm{R}_{\mathrm{c}}\right)$ поверхности частиц (коэффициент корреляции $0,7 \ldots 0,9)$, а при нагрузках выше 200 МПа связь не выявлена. 


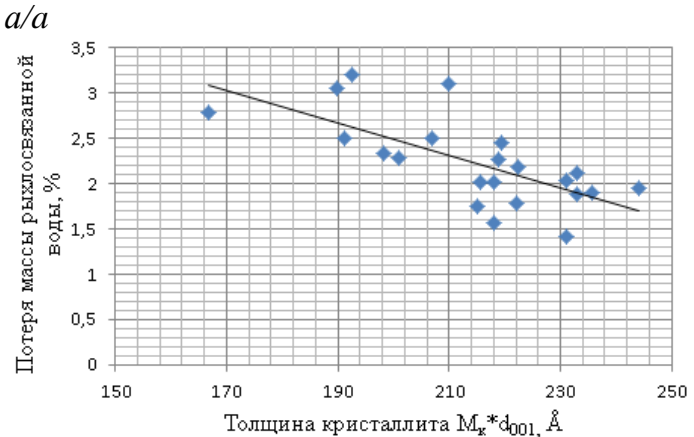

$B / c$

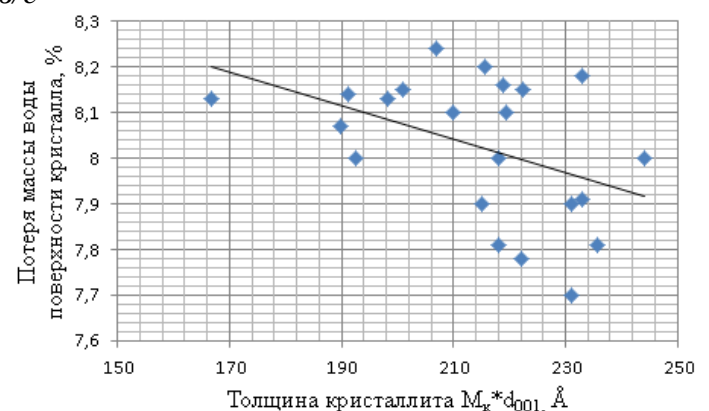

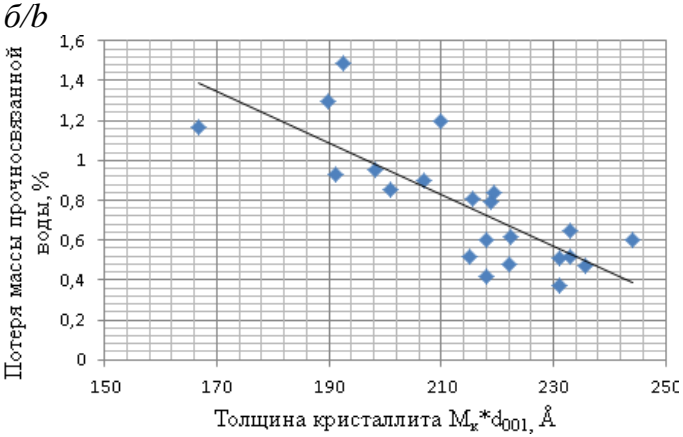

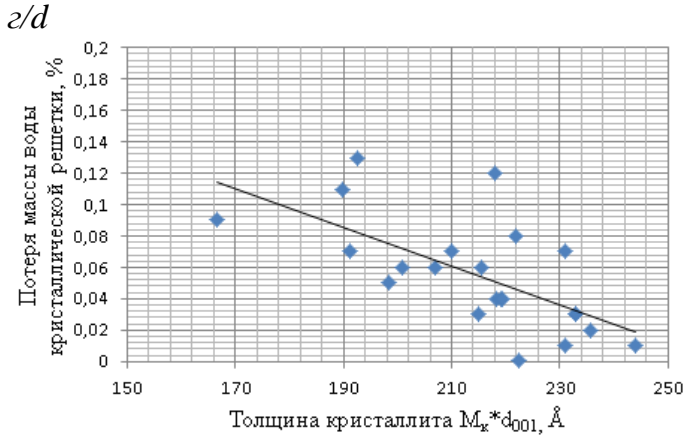

Рис. 4. Диаграмма рассеяния показателя Мк (толщуиной кристаллита (минерала), А) и потери массы связанной водbl, \%: а) рыхлосвязанной воды; б) прочносвязанной воды; в) воды поверхности кристаллита (минерала); г) кристаллической решетки минерала

Fig. 4. Scattering diagram of the Mc index (crystallite thickness, A) and the mass loss of bound water, \%: a) loosely bound water; b) tightly bound water; $c$ ) water of the crystallite surface; d) mineral crystal lattice

$a / a$

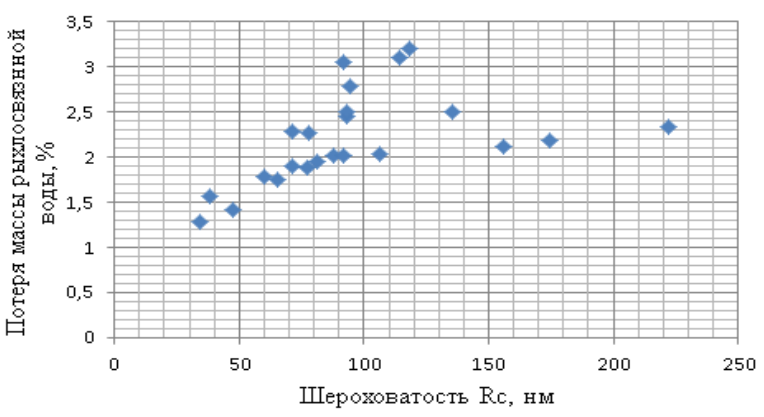

$B / c$

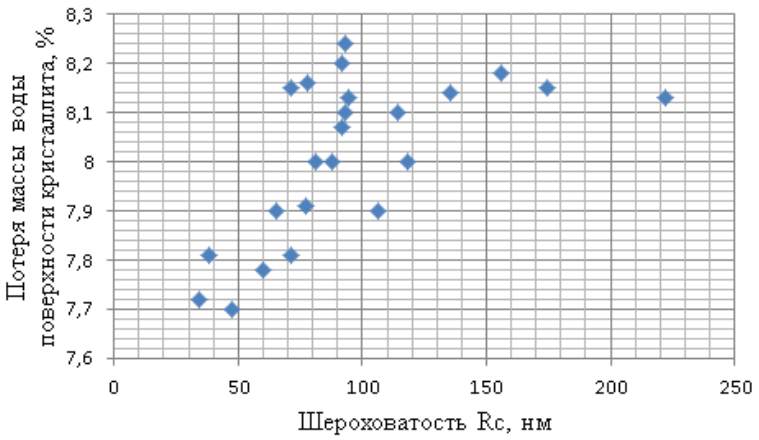

$\sigma / b$

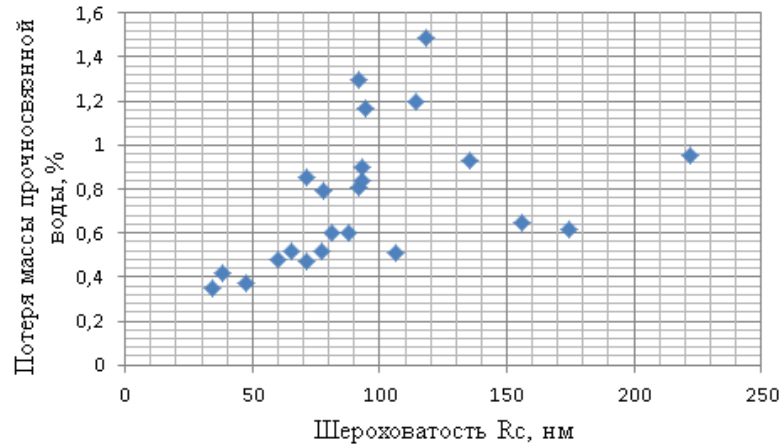

$2 / d$

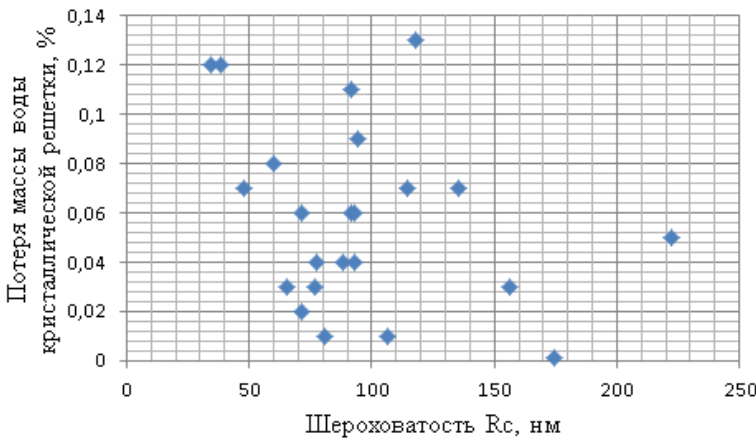

Рис. 5. Диаграмма рассеивания показателя $R_{c}$ (иероховатость, нм) и потери массы: а) рыхлосвязанной воды; б) прочносвязанной воды; в) воды поверхности кристаллита (минерала); г) кристаллической решетки минерала

Fig. 5. Scattering diagram of the $R_{c}$ index (roughness, $n m$ ) and weight loss: a) loosely bound water; b) tightly bound water; c) water of the crystallite surface; d) mineral crystal lattice 
Вопросами классификации воды в грунтах занимались многие ученые: А.Ф. Лебедев, Дж. Боюкос, А.А. Роде, С.И. Долгов, Р.И. Злочевская, Е.М. Сергеев, В.Т. Трофимов, В.И. Осипов, В.Н. Соколов и др. Все классификации отличаются большим терминологическим разнообразием.
Полученные экспериментальные данные с позиций размерности структурных элементов грунта согласуются по физическому смыслу с классификацией связанной воды в глинах, разработанной Е.М. Сергеевым и др. Соотношение классификаций приведено в табл. 3.

Таблица 3. Сравнение классификации связанной воды, предложенной авторами, с классификацией по Е.М. Сергееву и $о р$.

Table 3. Comparison of the bound water classification proposed by the authors with the classification according to E.M. Sergeev et al.

\begin{tabular}{|c|c|c|}
\hline $\begin{array}{l}\text { Класс связанной } \\
\text { воды } \\
\text { Bound water class }\end{array}$ & $\begin{array}{c}\text { Классификация, предложенная авторами } \\
\text { Classification proposed by the authors }\end{array}$ & $\begin{array}{l}\text { Классификация по Е.M. Сергееву } \\
\text { Classification by E.M. Sergeev }\end{array}$ \\
\hline 1 & $\begin{array}{l}\text { рыхлосвязанная вода поверхности коллоидов } \\
\text { loosely bound water on the surface of colloids }\end{array}$ & $\begin{array}{l}\text { осмотическая вода } \\
\text { osmotic water }\end{array}$ \\
\hline 2 & $\begin{array}{l}\text { прочносвязанная вода поверхности коллоидов } \\
\text { firmly bound water on the surface of colloids }\end{array}$ & $\begin{array}{l}\text { рыхлосвязанная «вторично ориентированная вода полисло- } \\
\text { ев» или пленочная вода } \\
\text { loosely bound «secondary oriented water of multilayers» or film } \\
\text { water }\end{array}$ \\
\hline 3 & $\begin{array}{l}\text { вода поверхности минералов (кристаллитов) } \\
\text { surface water of minerals (crystallites) }\end{array}$ & $\begin{array}{l}\text { прочносвязанная «вода ближней гидратации ионов» и «ба- } \\
\text { зальных поверхностей минералов» } \\
\text { tightly bound «water of near hydration of ions» and «basal sur- } \\
\text { faces of minerals» }\end{array}$ \\
\hline 4 & $\begin{array}{l}\text { вода кристаллической решетки минералов } \\
\text { mineral lattice water }\end{array}$ & $\begin{array}{l}\text { прочносвязанная вода «углов и сколов поверхности кри- } \\
\text { сталлической решетки» } \\
\text { tightly bound water of «corners and cleavages of the crystal lat- } \\
\text { tice surface» }\end{array}$ \\
\hline
\end{tabular}

Таким образом, в каолинитовых глинах, подверженных высоким давлениям, происходит изменение морфологии частицы и как следствие изменение удельной поверхности, что оказывает влияние на сорбционную активность.

\section{Заключение}

На основании результатов опытных данных и анализа термограмм выделено четыре пика потери массы воды, в соответствии с этим предложена классификация связанной воды в глине: рыхлосвязанная вода поверхности коллоидов; прочносвязанная вода поверхности коллоидов; вода поверхности минералов; вода кристаллической решетки. Воздействие высокого давления на массу удаляемой воды неоднозначно. Полученная классификация связан-

\section{СПИСОК ЛИТЕРАТУРЫ}

1. О природе изменения свойств связанной воды в глинах под действием повышающих температур и давлений / Р.И. Злочевская, В.А. Королев, З.А. Кривошеева, Е.М. Сергеев // Вестник Московского университета. Серия: Геология. 1977. - № 3. - С. 80-96.

2. О природе изменения состава и свойств глинистых пород в процессе литогенеза / З.А. Кривошеева, Р.И. Злочевская, В.А. Королев, Е.М. Сергеев // Вестник Московского университета. Серия: Геология. - 1977. - № 4. - С. 60-73.

3. Гойло Э.А., Котов Н.В., Франк-Каменецкий В.А. Экспериментальное исследование влияния давления и температуры на кристаллические структуры каолинита, иллита и монтмориллонита // Физические методы исследования осадочных пород. - М.: Наука, 1966. - С. 123-129.

4. Франк-Каменецкий В.А., Котов Н.В., Гойло Э.А. Изменение структуры глинистых минералов в различных темодинамических условиях // Рентгенография минерального сырья. 1970. - № 7. - C. 166-174.

5. The effect of micronization on kaolinites and their sorption behavior / G. Suraj, C.S.P. Iyer, S. Rugmini, M. Lalithambika // Applied Clay Science. - 1997. - V. 12. - P. 111-130. DOI: 10.1016/S0169-1317(96)00044-0 ной воды соотносится с классификацией, предложенной Е.М. Сергеевым.

Влияние стрессового давления на градиент потери массы воды неоднозначно. Это связано с тем, что под давлением происходит образование несовершенств (дефектов) структуры частицы, как следствие изменяется энергетический потенциал и сорбционная активность глинистых частиц. При этом выявлена тесная связь между показателем шероховатости и градиентом удаляемой связанной воды в интервале давлений от 0 до $200 \mathrm{MПа.} \mathrm{При} \mathrm{давлениях} \mathrm{от} 200$ до $800 \mathrm{MПа}$ какую-либо связь установить не удалось.

Таким образом, при сжатии в каолинитовой глине изменяется структура, морфология частиц, содержание различных форм связанной воды, что в значительной мере может определять ее свойства.

6. Королев В.А., Нестеров В.С. Физико-химические закономерности изменения электрических зарядов частиц глинистых грунтов // Инженерная геология. - 2017. - № 4. - С. 50-60. DOI: 10.25296/1993-5056-2017-4-50-60

7. Кара-Сал Б.К., Сапелкина Т.В. Повышение адсорбционных свойств глинистых пород Тувы в зависимости от методов активации // Актуальные проблемы современной науки. - 2012. - № 5. - С. 158-162.

8. Лучицкий И.В., Громин В.И., Ушаков Г.Д. Эксперименты по деформации горных пород в обстановке высоких давлений и температур. - Новосибирск: Изд-во «Наука», 1967. - 75 с.

9. Котельников Д.Д., Конюхов А.И. Глинистые минералы осадочных пород. - М.: Недра, 1986. - 247 с.

10. Осипов В.И., Соколов В.Н. Глины и их свойства. - М.: ГЕОС, 2013. $-576 \mathrm{c}$.

11. Шлыков В.Г. Рентгеновский анализ минерального состава дисперсных грунтов. - М.: ГЕОС, 2006. - 176 с.

12. Влияние давления на структуру каолинита в огнеупорных глинах Нижне-Увельского месторождения по данным ИКспектроскопии / О.С. Ситева, Н.А. Медведева, В.В. Середин, Д.В. Иванов, К.А. Алванян // Известия Томского политехнического университета. Инжиниринг георесурсов. - 2020. T. 331. - № 6. - C. 208-217. 
13. Exploring the relationship between th(iv) adsorption and the structure alteration of phlogopite / H. Wu, P. Liu, W. Wu, Q. Fan, X. Zhao, P. Li, J. Liang, S. Qiang // Applied Clay Science. 2018. - V. 152. - P. 295-302. DOI: 10.1016/j.clay.2017.11.026

14. Galan E., Aparicio P., Gonzalez Â. The effect of pressure on order/disorder in kaolinite under wet and dry conditions // Clays and Clay Minerals. - 2006. - V. 54. - № 2. - P. 230-239. DOI: 10.1346/CCMN.2006.0540208

15. Defects in structure as the sources of the surface charges of kaolinite / Xiaoyan Zhu, Zhichao Zhu, Xinrong Lei, Chunjie Yan // Applied Clay Science. - 2016. - V. 124-125. - P. 127-136.

16. Madejova J., Gates W.P., Petit S. IR Spectra of Clay Minerals // Developments in Clay Science. - 2017. - V. 8. - P. 107-149.

17. Методика оценки напряженного состояния горных пород / В.В. Середин, А.С. Хрулев, А.В. Растегаев, В.И. Галкин // Горный журнал. -2020 . - № 2. - С. 30-34.

18. Changes of energy potential on clay particle surfaces at high pressures / V.V. Seredin, A.V. Rastegaev, V.I. Galkin, G.A. Isaeva,
T.Yu. Parshina // Applied Clay Science. - 2018. - V. 155. - P. 8-14. DOI: 10.1016/j.clay.2017.12.042

19. Changes in physical-chemical properties of clay under compression / V.V. Seredin, A.V. Rastegayev, E.G. Panova, N.A. Medvedeva // International Journal of Engineering and Applied Sciences. - 2017. - V. 4. - № 3. - P. 22-29.

20. Изменение сил адгезии на поверхности частиц при обработке монтмориллонитовой глины высоким давлением / М.В. Федоров, И.В. Лунегов, Н.А. Медведева, М.Ф. Леонович, А.В. Растегаев // Вестник ПНИПУ. Геология. Нефтегазовое и горное дело. - 2019. - Т. 19. - № 1. - С. 26-38.

21. Changes in adhesion force on kaolin under pressures / V.V. Seredin, M.V. Fyodorov, I.V. Lunegov, V.I. Galkin // AIP Conference Proceedings. - 2020. - V. 2216 - P. 040004.

22. Seredin V.V., Khrulev A.S. Variations of temperature in specimens of rocks and geomaterials under failure // Journal of Mining Science. - 2016. - V. 52. - P. 683-688.

Поступила 19.04.2021 2.

\section{Информация об авторах}

Cередин B.B., доктор геолого-минералогических наук, заведующий кафедрой инженерной геологии и охраны недр Пермского национального исследовательского университета.

Ядзинская М.P., кандидат геолого-минералогических наук, доцент кафедры инженерной геологии и охраны недр Пермского национального исследовательского университета.

Андрианов А.В., научный сотрудник ООО НИППППД «Недра». 
UDC 552.525

\title{
CLASSIFICATION OF BOUND WATER FORMS IN KAOLINITIC CLAYS
}

\author{
Valery V. Seredin', \\ seredin@nedra.perm.ru \\ Marina R. Yadzinskaya ${ }^{1}$, \\ marinayadzinskaya@mail.ru \\ Andrey V. Andrianov², \\ andrianov@nedra.perm.ru \\ 1 Perm State National Research University, \\ 15, Bukirev street, Perm, 614068, Russia. \\ 2 «Nedra», \\ 13a, Lev Shatrov street, Perm, 614064, Russia.
}

Relevance. Water is the most important component of soils, as it influences the main geological processes. This is due to the peculiarities of its composition and structure. Many scientists have studied the issue of the content of bound water in clays. However, experiments on this issue are not enough.

The purpose of this work is to study the forms of bound water in kaolinite clays squeezed out at high pressures, as well as to reveal the relationship between the loss of water masses under pressure and thermodynamic parameters.

The object of the research is kaolinite clays.

Method. To achieve this goal, samples were prepared with various degrees of compression under pressure, and then thermogravimetric and diffractometric analyzes were performed.

The results of experimental data and analysis of thermograms made it possible to identify four peaks of water mass loss, in accordance with this, a classification of bound water in clay was proposed: loosely bound water on the surface of colloids; firmly bound water on the surface of colloids; mineral surface water; crystal lattice water. The impact of high pressure on the mass of removed water is ambiguous. This is due to the fact that the formation of defects occurs under pressure, as a result, the energy potential and sorption activity of clay particles change. At the same time, a close relationship was revealed between the roughness index and the gradient of the removed bound water in the pressure range from 0 to $200 \mathrm{MPa}$. Relationship is not established at pressures from 200 to $800 \mathrm{MPa}$.

\section{Key words:}

Kaolinite clay, forms of bound water, thermogravimetry, pressure, specific surface area, roughness, sorption activity.

\section{REFERENCES}

1. Zlochevskava R.I., Korolev V.A., Krivosheeva Z.A., Sergeev E.M. $\mathrm{O}$ prirode izmeneniya svoystv svyazannoy vody $\mathrm{v}$ glinakh pod deystviem povyshayushchikh temperatur i davleniy [On the nature of changes in the properties of bound water in clays under the influence of increasing temperatures and pressures]. Vestnik Moskovskogo universiteta. Series: Geology, 1977, no. 3, pp. 80-96.

2. Krivosheeva Z.A., Zlochevskaya R.I., Korolev V.A., Sergeev E.M. $O$ prirode izmeneniya sostava i svoystv glinistykh porod $v$ protsesse litogeneza [On the nature of changes in the composition and properties of clay rocks during lithogenesis]. Vestnik Moskovskogo universiteta. Series: Geology, 1977, no. 4, pp. 60-73.

3. Goilo E.A., Kotov N.V., Frank-Kamenetskii V.A. Eksperimentalnoe issledovanie vliianiya davleniya i temperatury na kristallicheskie struktury kaolinita, illita i montmorillonita [Experimental study of the effect of pressure and temperature on the crystal structures of kaolinite, illite and montmorillonite]. Fizicheskie metody issledovaniia osadochnykh porod [Physical methods for studying sedimentary rocks]. Moscow, Nauka Publ., 1966. pp. 123-129.

4. Frank-Kamenetskii V.A., Kotov N.V., Goilo E.A. Izmenenie struktury glinistykh mineralov v razlichnykh temodinamicheskikh usloviiakh [Changes in the structure of clay minerals under different temodynamic conditions]. Rentgenografiia mineralnogo syria, 1970, no. 7, pp. 166-174.

5. Suraj G., Iyer C.S.P., Rugmini S., Lalithambika M. The effect of micronization on kaolinites and their sorption behavior. Applied Clay Science, 1997, vol. 12, pp. 111-130. DOI: 10.1016/S01691317(96)00044-0

6. Korolev V.A., Nesterov V.S. Physico-chemical regularities of changes of the clay soil particles electrical charge. Inzhenernaia geologiia, 2017, no. 4, pp. 50-60. In Rus. DOI: 10.25296/19935056-2017-4-50-60
7. Kara-Sal B.K., Sapelkina T.V. Povyshenie adsorbtsionnykh svoystv glinistykh porod Tuvy v zavisimosti ot metodov aktivatsii [Increasing the adsorption properties of clay rocks of Tuva, depending on the activation methods]. Aktualnye problemy sovremennoy nauki, 2012, no. 5, pp. 158-162.

8. Luchitskiy I.V., Gromin V.I., Ushakov G.D. Eksperimenty po deformatsii gornykh porod $v$ obstanovke vysokikh davleniy i temperatur [Experiments on deformation of rocks in environment of high pressures and temperatures]. Novosibirsk, Nauka Publ., 1967. $75 \mathrm{p}$

9. Kotelnikov D.D., Konyukhov A.I. Glinistye mineraly osadochnykh porod [Clay minerals of sedimentary rocks]. Moscow, Nedra Publ., 1986. $247 \mathrm{p}$.

10. Osipov V.I., Sokolov V.N. Gliny i ikh svoystva [Clays and their properties]. Moscow, GEOS Publ., 2013. 576 p.

11. Shlykov V.G. Rentgenovskiy analiz mineralnogo sostava dispersnykh gruntov [X-ray analysis of the mineral composition of dispersed soils]. Moscow, GEOS Publ., 2006. 176 p.

12. Siteva O.S., Medvedeva N.A., Seredin V.V., Ivanov D.V., Alvanian K.A. Influence of pressure on kaolinite structure in fire-clays of the nizhne-uvelskoe deposit by IR spectroscopy Bulletin of the Tomsk Polytechnic University, Geo Assets Engineering, 2020, vol. 331, no. 6, pp. 208-217. In Rus.

13. Wu H., Liu P., Wu W., Fan Q., Zhao X., Li P., Liang J., Qiang S. Exploring the relationship between th(iv) adsorption and the structure alteration of phlogopite. Applied Clay Science, 2018, vol. 152, pp. 295-302. DOI: 10.1016/j.clay.2017.11.026

14. Galan E., Aparicio P., Gonzalez Â. The effect of pressure on order/disorder in kaolinite under wet and dry conditions. Clays and Clay Minerals, 2006, vol. 54, no. 2, pp. 230-239. DOI: 10.1346/CCMN.2006.0540208

15. Xiaoyan Zhu, Zhichao Zhu, Xinrong Lei, Chunjie Yan. Defects in structure as the sources of the surface charges of kaolinite. Applied Clay Science, 2016, vol. 124-125, pp. 127-136. 
16. Madejova J., Gates W.P., Petit S. IR Spectra of Clay Minerals. Developments in Clay Science, 2017, vol. 8, pp. 107-149.

17. Seredin V.V., Khrulev A.S., Rastegaev A.V., Galkin V.I. Procedure of stress state assessment in rocks. Gornyi Zhurnal, 2020, vol. 2, pp. 30-34.

18. Seredin V.V., Rastegaev A.V., Galkin V.I., Isaeva G.A, Parshina T.Yu. Changes of energy potential on clay particle surfaces at high pressures. Applied Clay Science, 2018, vol. 155. pp. 8-14. DOI: 10.1016/i.clay.2017.12.042

19. Seredin V.V., Rastegayev A.V., Panova E.G., Medvedeva N.A Changes in physical-chemical properties of clay under compression. International Journal of Engineering and Applied Sciences, 2017 , vol. 4, no. 3, pp. 22-29.
20. Fedorov M.V., Lunegov I.V., Medvedeva N.A., Leonovich M.F., Rastegaev A.V. Changes in adhesion forces on the surface of particles during the processing of montmorillonite clay by high pressure. Vestnik PNRPU, 2019, vol. 19, no. 1, pp. 26-38. In Rus.

21. Seredin V.V., Fyodorov M.V., Lunegov I.V., Galkin V.I. Changes in adhesion force on kaolin under pressures. AIP Conference Proceedings, 2020, vol. 2216, pp. 040004

22. Seredin V.V., Khrulev A.S. Variations of temperature in specimens of rocks and geomaterials under failure. Journal of Mining Science, 2016, vol. 52, pp. 683-688.

Received: 19 April 2021.

\section{Information about the authors}

Valeriy V. Seredin, Dr. Sc., professor, head of the Department of Engineering Geology, Perm State National Research University.

Marina R. Yadzinskaya, Cand. Sc., associate professor, Perm State National Research University. Andrey V. Andrianov, researcher, «Nedra». 